\title{
Preparation and Characterization of Various Membrane Morphologies for Lateral Flow Immunoassay Development
}

\author{
A. L. Ahmad ${ }^{1 *}$, S. C. Low ${ }^{2}$, S. R. Abd Shukor ${ }^{3}$ \& A. Ismail ${ }^{4}$ \\ ${ }^{1,2 \& 3}$ School of Chemical Engineering, Engineering Campus, Universiti Sains Malaysia, Seri Ampangan, 14300 \\ Nibong Tebal, S.P.S, Penang, Malaysia \\ ${ }^{4}$ Institute for Research in Molecular Medicine, Health Campus, Universiti Sains Malaysia, 16150 Kubang \\ Kerian, Kelantan, Malaysia
}

\begin{abstract}
Lateral flow in nitrocellulose membrane is widely used as the transport medium in immunological test strips. The immunoassay performance depends greatly on the binding mechanism on membrane surface. If the membrane structures cotld be controlled precisely, various kinds of immunological analysis could be performed effectively and accurately. This study is aimed at a quantitative understanding on (1) the sensitivity of protein quantification on membrane surface by using densitometer and (2) comparison of the protein binding ability on different membrane surface pore structures. Concentration of immobilised protein on membrane surface was measured as a function of colour intensity, which is initially stained with Ponceau S. The findings showed that membrane morphologies significantly affect the sensitivity of membrane protein binding ability. Depending on the membrane pore structures, different red spot sharpness and intensities were observed from the stained protein dot. Membrane with smaller pore creates higher protein immobilization density and thus, increases the sensitivity level of the assay. However, larger membrane pore structure is necessary to induce rapid migration rate for faster assay.
\end{abstract}

Keywords: Nitrocellulose membrane, morphology, immunoassay, microstructure, pore size

\subsection{INTRODUCTION}

Lateral flow immunoassays have been widely introduced in the field of food science and healthcare $[1,2]$, due to their sensitivity, rapid testing, inexpensive manufacturing cost and easy to operate procedure [3]. A large number of testings are available for the detection of certain infectious diseases [4], food hygiene [5, 6], fertility test and etc. This will then translate to swift detection of hazardous substance in food prior to human consumption, which then helps to save lives.

Both immunoassay performance and its effectiveness depend greatly on the transport rate of aqueous solution through membrane pores and

\footnotetext{
* Correspondence to: A. L. Ahmad (email:chlatif@eng.usm.my)
}

the binding mechanism on membrane surface [7] If the membrane surface and internal layer structures could be controlled precisely, various kinds of immunological analysis could be performed effectively and accurately [8]. Thus, membrane plays an important role on the efficiency of a diagnostic test strip.

Morphology of the selected membrane is crucial to attain the sensitivity of a diagnostic assay $[9,10]$. In the production of an immuno diagnostic test strip, microporous lateral flow nitrocellulose (NC) membrane is known as the popular transport medium due to its specific binding affinity to amino acids. Different pores structure is used to immobilize various detecting reagents with varying molecular size. Lower membrane pore structure has higher membrane surface area and able to bind more detecting 
reagent on the membrane capture zone, thus, more sensitive assay is produced [7]. However, it will result in a slower performance assay, which means the analyte took longer time to move along the membrane strip of a defined length.

In immunodiagnostic tests, protein is the most common sample applied to a solid membrane surface. The interaction of protein with microporous membrane will significantly reflect the membrane morphology. Immobilized amino group on membrane surface was able to be detected by spectrophotometry [11] or densitometry [12]. In spectrophotometry detection, protein quantification was done by measuring the absorption spectra of the sample solution using spectrophotometer at $529 \mathrm{~nm}$ [11]. By using densitometer, the immobilized protein dot on membrane surface was measured based on the colour densities of the membrane reflecting surlace [12, 13].

To date, there have been no reports on chromatographic performance of an immunoassay, which depends on various membrane morphologies. Hence, this study is aimed at a quantitative understanding of membrane morphology, which governs the performance of immunoassays. In this report, we were interested in (a) determining the sensitivity of membrane protein quantification by using densitometer and (b) comparison of the protein binding ability on different membrane surface pore structures.

\subsection{METHODS/THEORY}

\subsection{Materials}

Raw materials involved in membrane formulation are nitrocellulose (NC) polymer with 11.8-
$12.3 \%$ nitrate and $30 \%$ of alcohol, methyl acetate (MA) (the solvent), iso-propanol (IP) (nonsolvent), glycerol and water. $0.05 \mathrm{M}$ phosphate buffer at pH 7.0 served as a buffer for the protein solution. The $0.05 \mathrm{M}$ phosphate buffer was prepared by adding $21.1 \mathrm{ml}$ of $1 \mathrm{M}$ potassium phosphate monobasic and $28.9 \mathrm{ml}$ of $1 \mathrm{M}$ potassium phosphate dibasic and made up to $1000 \mathrm{ml}$ with deionized water. Bovine serum albumin (BSA) and ponceau $\mathrm{S}$ solution were purchased from Sigma, USA.

\subsection{Membrane Preparation}

Membranes were prepared by dry phase inversion method [14] according to the design blends and process factors as stated in Table 1 . The casting process was carried out at ambient temperature and performed with a membrane auto casting machine; with a casting speed of $100 \mathrm{rpm}$ [15, 16]. Before use, the membranes were dried in a vacuum oven overnight at $40^{\circ} \mathrm{C}$.

\subsection{Membrane Characterizations}

The average pore sizes of the synthesised membrane were measured from the membrane images scanned by Field Emission Scanning Electron Microscopy (FESEM, Supra 35VP, Germany), using magnifications of 2000 . The measurements were taken from an average of six specimens for each membrane sample. Meanwhile, the porosity of the synthesized membranes, $\varepsilon$, was calculated with the formula postulated by Yamane $e t$ al. and Meier et al. [17, 18].

$$
\varepsilon=\left[1-\frac{V_{E}}{V_{A}}\right] \times 100
$$

Table 1 Membrane casting dope composition

\begin{tabular}{lccccc}
\hline & \multicolumn{4}{c}{ Casting dope composition } \\
Component & M1 & M2 & M3 & M4 & M5 \\
\hline Polymer (\%) & 3 & 4 & 5 & 4 & 4 \\
Solvent (\%) & 83 & 82 & 81 & 82 & 82 \\
Nonsolvent + Additives (\%) & 14 & 14 & 14 & 14 & 14 \\
Initial Cast Thickness $(\mu \mathrm{m})$ & 700 & 700 & 700 & 600 & 800 \\
\hline
\end{tabular}


Table 2 Membrane characterization

\begin{tabular}{cccc}
\hline Membrane Sample & Porosity, $\%$ & Yield Thickness, $\mu \mathrm{m}$ & Average Membrane Pore Size, $\boldsymbol{\mu m}$ \\
\hline M1 & $76.40 \pm 2.1$ & $83 \pm 6$ & $5.3 \pm 0.2$ \\
M2 & $75.81 \pm 1.7$ & $126 \pm 5$ & $5.0 \pm 0.3$ \\
M3 & $74.68 \pm 1.9$ & $153 \pm 7$ & $4.6 \pm 0.3$ \\
M4 & $73.29 \pm 2.0$ & $96 \pm 5$ & $4.1 \pm 0.2$ \\
M5 & $76.05 \pm 2.3$ & $139 \pm 8$ & $6.8 \pm 0.4$ \\
\hline
\end{tabular}

The apparent volume of membrane (VA) was calculated based on the film thickness and film surface area $(2 \mathrm{~cm} \times 1 \mathrm{~cm})$. The existent volume of membrane $\left(V_{\mathrm{E}}\right)$ was determined through the corresponding polymer density and membrane sample weight. Final thickness of the membrane was measured by micro thickness gauge (Mitutoyo 7301, Japan).

\subsection{Protein Immobilization}

A sample of $2 \mathrm{~cm} \times 10 \mathrm{~cm}$ membrane strip was cut from the synthesized membrane. BSA solutions $(0-20 \mathrm{mg} / \mathrm{ml})$ with $0.05 \mathrm{M}$ phosphate buffer, $\mathrm{pH}$ 7.0 were prepared and $1 \mu$ l of each solution was spotted on the membrane surfaces $[12,19]$. The membranes were then left to be air dried.

\subsection{Detection of Amino Groups Bound on Nitrocellulose Membrane}

Membrane with protein dots was immersed in a sufficient amount of Ponceau S staining solution for $5 \mathrm{~min}$. The membrane was rinsed with deionised water to wash off the membrane background [13]. It was then air dried at room temperature. The stained amino group on membrane surface was then scanned by Heiland electronic GmbH densitometer (TRD-4, Germany) at $560 \mathrm{~nm}$ on reflectance mode, with a measuring aperture of $3 \mathrm{~mm}$ in diameter.

For protein quantification, the membrane sample was first coated with mineral oil to increase the translucency of the background and brightness of the coloured spot [13]. The protein dot was measured based on the colour densities on the membrane reflecting surface and the total area of the stained protein dot. Each protein dot value represents an average value of 6 spots.

\subsection{Results and Discussions}

Before the performance of the membrane was tested, characterization results of the synthesized membrane, such as pore size, porosity, and thickness were tabulated in Table 2. Varying concentrations of protein solutions with constant volume of $1 \mu$ were initially deposited on the membrane surface, to determine the membrane protein capture ability at a fixed location. The membrane sample was then immersed into Ponceau $\mathrm{S}$ solution for protein staining. Ponceau $\mathrm{S}$ was selected as the protein stain because it has relatively low nonspecific binding (low background) to the nitrocellulose membrane [11] and is also a quick stain to perform.

From Figure 1, it was observed that the membrane sample shows sharp and high precision of protein dots. When the Ponceau S solution came into contact with the initial immobilized protein dot on the membrane surface, a visible red spot appeared as it accumulates at the position of the protein dot. The protein dot that is initially deposited on the membrane surface would not easily be washed out by capillary force of Ponceau $S$ solution if the membrane contained high protein binding ability. From the sharp red dots which appeared in Figure 1, it can be confirmed that the synthesized membrane has precise protein binding ability.

However, plain observation on the sharpness of the red spots that appeared on the membrane surface is not prove enough to represent the membrane binding performance. As can be observed from Figure 1, the colour that develops on the membrane surfaces are different for varying protein concentration as expected. In fact, this developed colour is proportionate to the amount of protein bound on the membrane strip. 


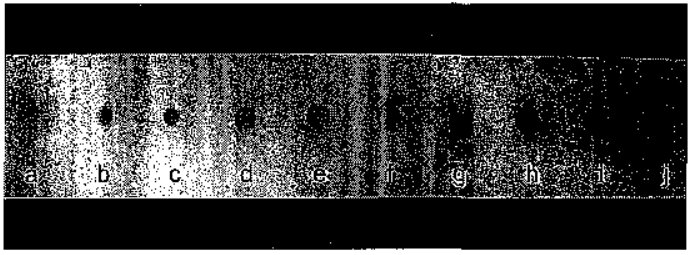

Figure 1 Stained protein dots (immobilized protein volume: $1 \mu \mathrm{l}$ ) on nitrocellulose membrane with varying protein concentrations (a: $0.1 \mathrm{mg} / \mathrm{ml}$, b: $0.5 \mathrm{mg}$ / $\mathrm{ml}$, c: $1 \mathrm{mg} / \mathrm{ml}$, d: $2 \mathrm{mg} / \mathrm{ml}$, e: $3 \mathrm{mg} / \mathrm{ml}$, f: $4 \mathrm{mg} / \mathrm{ml}$, g: $5 \mathrm{mg} / \mathrm{ml}$, h: $10 \mathrm{mg} / \mathrm{ml}$, i: $15 \mathrm{mg} / \mathrm{ml}$ and $\mathrm{j}: 20 \mathrm{mg} / \mathrm{ml}$ )

Figure 2 shows the colour densities for the equivalent volume of protein solutions $(1 \mu \mathrm{l})$ with varying concentrations $(0.1 \mathrm{mg} / 1$ to $20 \mathrm{mg} / \mathrm{l})$ that were bound on the membrane surfaces. It was found that the colour densities for protein dots were increased proportionally to the quantity of the protein absorbed on the membrane. The linearity of the absorbance was maintained up to $5 \mathrm{mg} / \mathrm{ml}$, as shown in Figure 2(a). When the deposited protein concentration was over $5 \mathrm{mg} /$ $\mathrm{ml}$, the colour density of the protein dot reached a flat peak and less variation in colour density readings were observed (Figure $2(\mathrm{~b})$ ). This might be due to saturation of protein absorbing capacity on the membrane [12].

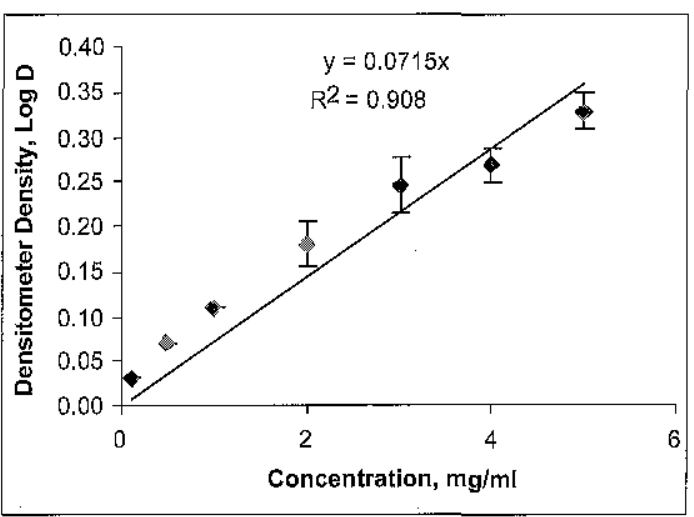

(a)
Another interesting observation was shown in Figure 3 . When constant spotting volume $(1 \mu \mathrm{l})$ of protein solutions was deposited on the membrane surface, it was observed that the diameter of protein spot area was larger for the higher concentration of protein solution. With higher protein concentration, the solution have greater diffusion rate to spread over on the membrane surface and therefore produced a bigger spot on the membrane. This observation leads to a fact that the initial concentration of solution affects the membrane performances. Higher protein concentration also contributes to the sharpness of the protein dot. In Figure 3(a), the total protein dot area appeared to increase gradually when higher protein concentration is deposited on the membrane surfaces. A similar observation was made for Figure 3 , where protein dot area reached a flat peak when the deposited protein concentration was over $10 \mathrm{mg} / \mathrm{ml}$.

In order to produce an effective and accurate immunoassay, effects of various membrane morphologies and pore sizes on the membrane protein binding ability were studied. The protein binding quantities for increasing polymer concentration in casting dope were shown in Figure 4(a). The higher polymer content in casting dope was produced from a membrane with smaller pore size and porosity, as shown in Table 2. In Figure 4(a), membrane with higher polymer content (i.e. smaller pore size) exhibits

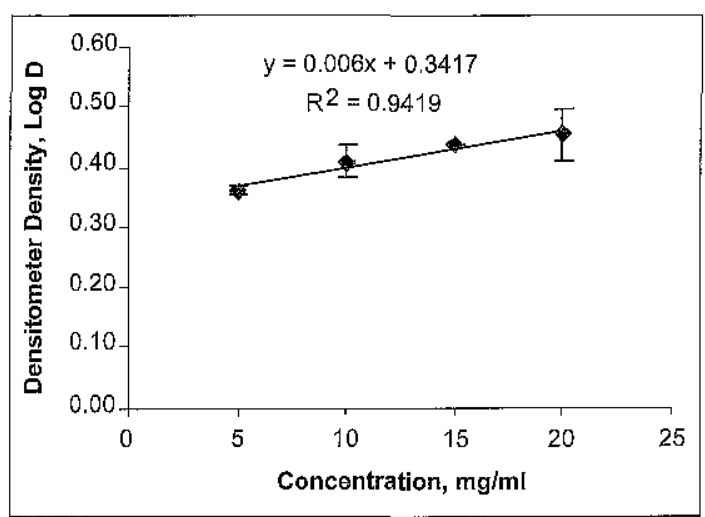

(b)

Figure 2 Colour densities for stained protein dots with increasing concentration of BSA with constant volume $(1 \mu \mathrm{l}$ per spot). Each protein dot value represents an average value of 6 spots and the bars represent the standard error. (a: $0.1-5 \mathrm{mg} / \mathrm{ml}$ per spot, b: $5-20 \mathrm{mg} / \mathrm{ml}$ per spot) 


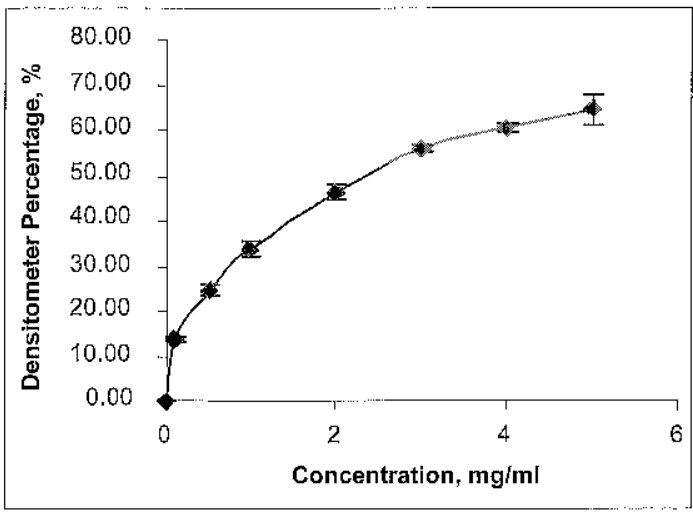

(a)

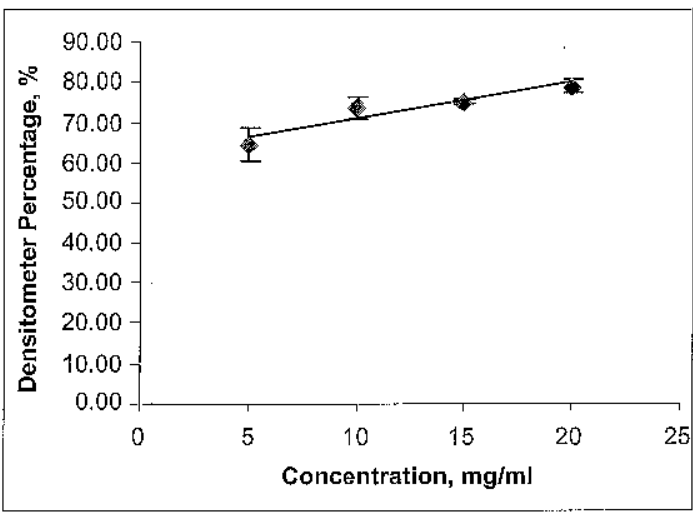

(b)

Figure 3 Densitometry dot area percentage (100\% of area percentage referred to measuring aperture with diameter of $3 \mathrm{~mm}$ or area $7.07 \mathrm{~mm}^{2}$ ) with increasing concentration of BSA with constant volume of $1 \mu \mathrm{l}$ per spot. (a: $0.1-5 \mathrm{mg} / \mathrm{ml}$ per spot, b: $5-20 \mathrm{mg} / \mathrm{ml}$ per spot)

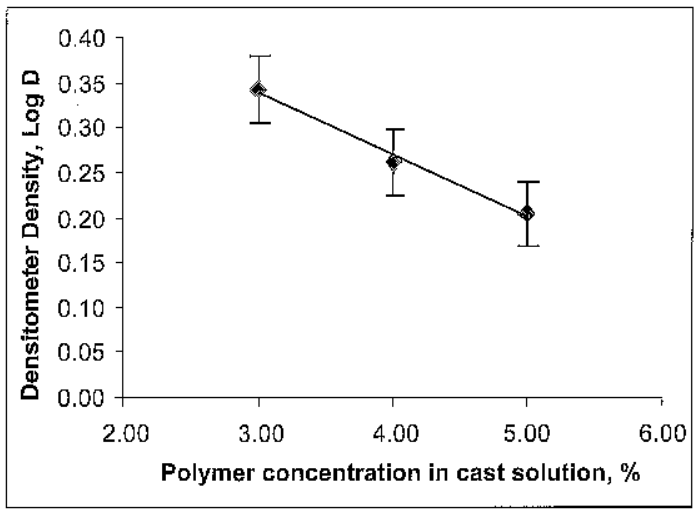

(a)

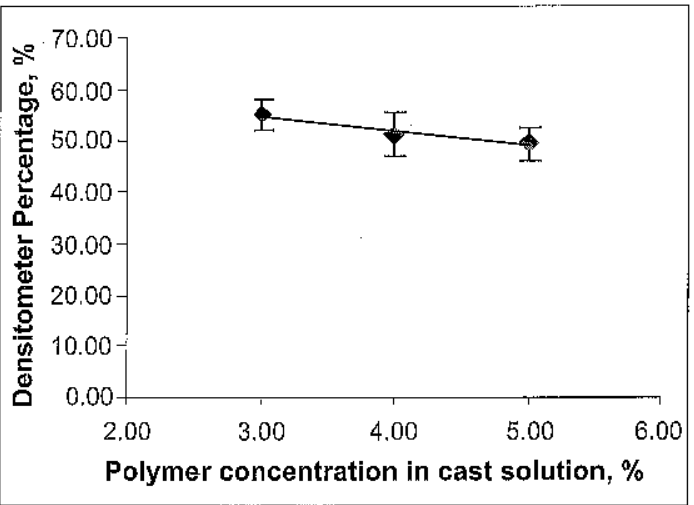

(b)

Figure 4 Effects of polymer concentration on stained protein dots with constant protein concentration $(2 \mathrm{mg} / \mathrm{ml})$ and volume $(1 \mu \mathrm{l})$. a: colour densities of stained protein dots, b: Densitometry dot area, with increasing polymer concentration in membrane cast dope

lower colour density of protein dot, i.e. lower protein binding capacity.

This is because membrane with smaller pores has a higher membrane total surface area. Hence, it will yield more density of protein molecules immobilized on the membrane pore matrix and provide higher protein binding on the membrane surface. Besides, the immobilized protein is able to bind firmly within the smaller polymer matrix, since more complex three-dimensional interconnected polymer structure appeared on the membrane layers with smaller pores. However, if the membrane pore is too small, it will create some close pores on the membrane surface and cause less protein to bind into it.

It was observed from Figure $4 \mathrm{~B}$ that the protein dot area was not much affected with the increase of polymer content in the synthesised membrane. Stained protein dot area was slightly decreased from $49.49 \%$ to $55.18 \%$ with increasing polymer content from $3 \%$ to $5 \%$ in the membrane casting dope. The slightly decreased protein dot volume was due to the higher diffusion resistance with membranes with smaller pores.

From Figure 5(a), it was shown that the membrane thickness does not significantly affect 


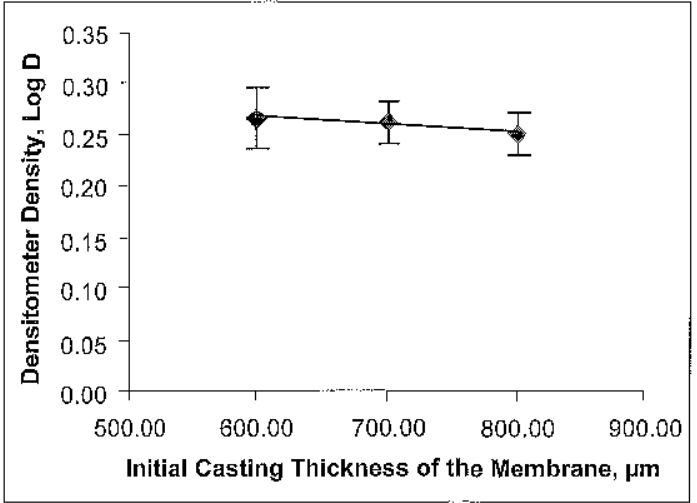

(a)

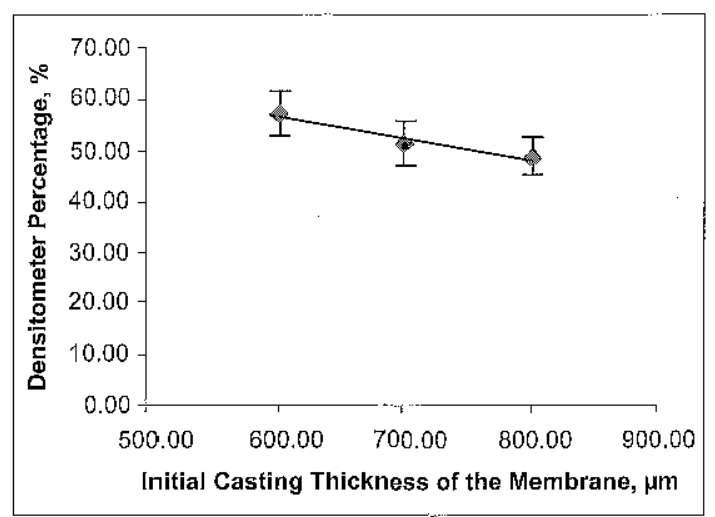

(b)

Figure 5 Effects of initial membrane casting thickness on stained protein dots with constant protein concentration $(2 \mathrm{mg} / \mathrm{ml})$ and volume $(1 \mu \mathrm{l})$. a: colour densities of stained protein dots, b: Densitometry dot area, with increasing polymer concentration in membrane cast dope

the colour densities of protein dots. Membrane with thinner initial cast thickness (M3 with smaller pore size) is able to bind larger amount of protein on the membrane surface, colour density of 0.27 , as compared to the thicker membrane sample (M5 with bigger pore size), colour density of 0.25 . The thicker membrane sample (M5) supposes to have higher colour density of protein dot, due to the higher numbers of internal membrane layers. Nevertheless, the increasing membrane cast thickness contributes to the formation of both macrovoids in the membrane interlayer as well as open pores on the membrane surfaces [16]. Thus, the total surface area for electrostatic binding between the protein and membrane was reduced compared to the thinner membrane thickness. However, the slight decrement of 0.02 in colour density with the increase of $200 \mu \mathrm{m}$ in the membrane initial cast thickness can be neglected. Similar with the values for colour densities, values for the stained protein dots area were almost constant for the membrane thickness increased from $600 \mu \mathrm{m}$ to $800 \mu \mathrm{m}$.

\subsection{CONCLUSION}

The aim of this study is to understand the relationship between membrane morphology and its binding ability in immunological analysis. The accuracy of the immunological test performance is largely influenced by membrane geometric control and homogenous distribution of protein dot solution on the membrane surfaces. It was found that the colour density of the stained protein dot increased linearly with increased protein concentration, until a stage where the colour density reached a flat peak. The higher polymer content in synthesized membrane provides a higher colour density of protein dot, due to the larger membrane surface area. However, initial cast thickness for the membrane did not significantly affect the protein absorption on the membrane surface, where, the colour density of the protein dots remains almost constant for membrane thicknesses of $600 \mu \mathrm{m}$ to $800 \mu \mathrm{m}$.

\section{ACKNOWLEDGEMENT}

The authors wish to thank the Science Fund by MOSTI (03-01-05-SF0133) and MTDC (6053014) for giving financial support in this project.

\section{REFERENCES}

[1] Wang, J., D. Johannsmann, M. Hollas, and V. Thom. 2006. Visualization of Capture Line Protein Binding in Nitrocellulose 
Diagnostic Membranes. Desalination. 199: 232-233.

[2] Hampl, J., M. Hall, N.A. Mufti, Y.-m.M. Yao, D.B. MacQueen, W.H. Wright, and D.E. Cooper. 2001. Upconverting Phosphor Reporters in Immunochromatographic Assays. Anal. Biochem. 288: 176-187.

[3] Newman, D.J. and C.P. Price. 1997. Principles and Practice of Immunoassay. New York: Stockton Press.

[4] Schramm, W., S.E. Wade, G.B. Angulo, P.C. Torres, and A. Burgess-Cassler. 1998. A Simple Whole-blood Test for Detecting Antibodies to Human Immunodeficiency virus. Clin. Diagn. Lab. Immunol. 5: 26326.5.

[5] Hatta, M., M.G.A. Goris, E. Heerkens, J. Gooskens, and H.L. Smits. 2002. Simple Dipstick Assay for the Detection of Salmonella Typhi-specific IgM Antibodies and the Evolution of the Immune Response in Patients with Typhoid Fever. Am. J. Trop. Med. Hyg. 66: 416-421.

[6] Aziah, I., M. Ravichandran, and A. Ismail. 2007. Amplification of ST50 Gene using Dry-reagent-based Polymerase Chain Reaction for the Detection of Salmonella Typhi. Diagn. Microbiol. Infect. Dis. 59: 373-377.

[7] Butler, J.E. 1991. Immunochemistry of Solid-Phase Immunoassay. United States: CPC Press.

[8] Mulder, M. 2003. Basic Principles of Membrane Technology. Netherlands: Kluwer Academic Publishers.

[9] Qian, S., and H.H. Bau. 2004. Analysis of Lateral Flow Biodetectors: Competitive Format. Anal. Biochem. 326: 211-224.

[10] Harvey, M.A., C.A. Audette, and R. Mcdonogh. 1996. The Use of Microporous Polymer Membranes in Immunoassays. IN: IVD Technology.

[11] Goldring, J.P.D., and L. Ravaioli. 1996. Solubilization of Protein-Dye Complexes on Nitrocellulose to Quantify Proteins Spectrophotometrically. Anal. Biochem. 242: 197-201.

[12] Bannur, S.V., S.V. Kulgod, S.S. Metkar, S.K. Mahajan, and J.K. Sainis. 1999. Protein Determination by Ponceau S Using Digital Color Image Analysis of Protein Spots on Nitrocellulose Membranes. Anal. Biochem. 267: 382-389.

[13] Morcol, T., and A. Subramanian. 1999. A Red-Dot-Blot Protein Assay Technique in the Low Nanogram Range. Anal. Biochem. 270: 75-82.

[14] Kesting, R.E. 1985. Synthetic Polymer Membranes: A Structural Perspective Second Edition. United State: John Wiley \& Sons Inc.

[15] Ahmad, A.L., S.C. Low, S.R.A. Shukor, and I. Asma. 2008. Synthesis and Characterization of Polymeric Nitrocellulose Membranes: Influence of Additives and Pore Formers on the Membrane Morphology. J. Appl. Polym. Sci. 108: 2550-2557.

[16] Ahmad, A.L., S.C. Low, and S.R.A. Shukor. 2007. Effects of Membrane Cast Thickness on Controlling the Macrovoid Structure in Lateral Flow Nitrocellulose Membrane and Determination of its Characteristics. Scr. Mater. 57: 743-746.

[17] Yamane, S., K. Takayama, and T. Nagai. 1998. Effect of Fractal Dimension on Drug Permeation through Porous Ethylcellulose Films. J. Control Release. 50: 103-109.

[18] Meier, M.M., L.A. Kanis, and V. Soldi, 2004. Characterization and Drug-permeation Profiles of Microporous and Dense Cellulose Acetate Membranes: Influence of Plasticizer and Pore Forming Agent. Int. J. Pharm. 278: 99-110.

[19] Moore, M.K., and S.M. Viselli. 2000. Staining and Quantification of Proteins Transferred to Polyvinylidene Fluoride Membranes. Anal. Biochem. 279: 241-242. 